\title{
ORBITAL GRANULOMATA ASSOCIATED WITH WIDESPREAD ANGIITIS*
}

\author{
BY \\ R. B. HARCOURT \\ Moorfields Eye Hospital, London
}

CONSIDERABLE attention has been paid in recent years to cases in which necrotic granulomata have been found in association with widespread lesions showing angiitis of the polyarteritis nodosa type. Occasionally the orbit is the site of such a granuloma.

Straatsma (1957), describing the ocular manifestations of Wegener's granulomatosis, and Cutler and Blatt (1956), making a similar survey of cases of lethal midline granuloma which they look upon as a more local manifestation of the same disease process, each quote a number of cases in which orbital granulomata were presenting or notable features of the disease. Walton (1958) describes proptosis as occurring in nearly 10 per cent. of such cases. Coop (1961) quotes a case of Wegener's granulomatosis (Faulds and Wear, 1960) presenting as an orbital pseudo-tumour, and Ring (1962) presents a similar case. Duke-Elder (1962), describing Wegener's granulomatosis, comments that "the condition is of considerable importance in ophthalmology, as it may first present, or only present, in the ocular or orbital tissues".

A new case is here reported in some detail in which signs of an orbital granuloma and generalized vasculitis co-existed, but which differed in many clinical aspects from the classical description of Wegener's granulomatosis, even though the granuloma histologically resembled those found in this condition.

\section{Case Report}

A man aged 58 years was first seen at another hospital in February, 1962, complaining of severe left-sided frontal and temporal headache associated with malaise and loss of weight. There was no history of allergy or of recent drug therapy.

Examination.-No abnormal neurological signs were found. Sinus and chest $x$ rays were normal, as were skull $x$ rays apart from possible bone destruction in the right pterygoid region. Urine examination normal. Blood pressure 160/90. Erythrocyte sedimentation rate was $80 \mathrm{~mm}$./ hr. Blood tests revealed a hypochromic anaemia with $\mathrm{Hb} 73$ per cent.

A left nasal discharge was noted, with superficial septal ulceration on that side. This was thought to be due to atrophic rhinitis associated with a deviated nasal septum, as the lesion healed with simple local medication.

Progress.-A month later, the patient developed a right lateral rectus paresis, slight right ptosis, and right papilloedema, and was referred to a neurosurgical unit for further investigation. On repeated skull $x$ rays, the right pterygoid changes previously noted were not thought to be significant. A lumbar puncture showed a normal pressure, and the only abnormality on examination of the fluid was a slightly raised protein content at $52 \mathrm{mg} . / 100 \mathrm{ml}$. The Wassermann reaction and Kahn test were negative in the cerebrospinal fluid and the blood. An air encephalogram and left carotid angiogram were normal.

Within a month, the extra-ocular movements became full again, but bilateral papilloedema persisted despite a normal cerebrospinal fluid pressure, and the severe headache continued. The patient was discharged from hospital with a tentative diagnosis of toxic cranial neuritis.

* Received for publication February 14, 1964. 
Three months later, in September, 1962, a lumbar puncture again showed a raised cerebrospinal fluid protein content $(120 \mathrm{mg} . / 100 \mathrm{ml}$.) and the erythrocyte sedimentation rate was $55 \mathrm{~mm}$. $/ \mathrm{hr}$.

In November, 1962, 9 months after he was first seen, the patient developed right proptosis with chemosis, reduced right ocular movements, and diminished right visual acuity. The total white blood cell count was $9,000 / \mathrm{c} . \mathrm{mm}$., with 10 per cent. eosinophils, and for the first time the urine contained red and white blood cells and hyaline casts, but no protein. 2 weeks later he suffered a large haematemesis for which he required transfusion, and a barium meal revealed a penetrating gastric ulcer at the incisura. A pectoral muscle biopsy showed no evidence histologically of polyarteritis nodosa, but as the signs now pointed to this as the diagnosis, he was treated with prednisolone $10 \mathrm{mg}$. three times daily despite the gastric ulceration. On this régime the proptosis rapidly decreased and the headache improved. In view of persistent gastric ulceration, however, it was thought wise to cease the steroid therapy and immediately his symptoms returned.

In February, 1963, the patient was transferred to St. Bartholomew's Hospital for further investigation. Marked right proptosis was present, with peripheral field loss, and visual acuity was reduced to counting fingers in that eye. The right optic disc showed signs of secondary optic atrophy, and the left disc margins were blurred. Apart from slight left facial weakness no other abnormal physical signs were found. The blood urea was $30 \mathrm{mg} . / 100 \mathrm{ml}$.

Operation.-A right central tarsorrhaphy was carried out prior to right superior orbital exploration and decompression on March 4, 1963. At operation a greyish mass was found infiltrating widely in the orbit. No extensive exploration was carried out to discover the limits of the lesion, but a portion of it and of the lateral rectus muscle were removed for histological examination. The roof and part of the lateral wall were removed to decompress the orbit.

Histological Examination.-The biopsy specimen (Figs 1 and 2) revealed widespread inflammatory changes in the orbital connective tissue which were concentrated in and around the walls of small blood vessels. Some vascular walls showed foci of necrosis as well as diffuse infiltration with polymorph eosinophils and neutrophils. There were also small areas of perivascular necrosis with a preponderance of eosinophils in the surrounding cellular aggregates.

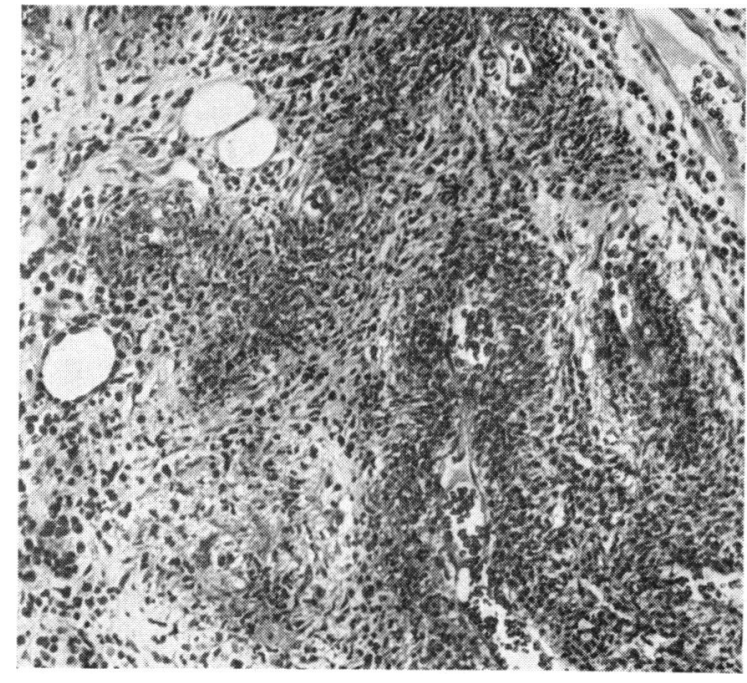

Fig. 1.-Biopsy from orbital granuloma, showing cellular infiltrates concentrated in and around the walls of small blood vessels. $\times 118$.

FIG. 2.-High-power view of small blood vessel, showing wall densely infiltrated with inflammatory cells. $\times 225$. 
Plasma cells, epithelioid cells, and fibroblasts were also seen, but there was no giant cell reaction. The picture was thus one of necrotizing angiitis of the polyarteritis type associated with extensive granulomatosis.

The extra-ocular muscle biopsy showed only non-specific inflammatory changes which could be traced in some cases to the walls of small blood vessels.

Result.-Post-operatively, in view of the histological findings, the persistently high erythrocyte sedimentation rate $(68 \mathrm{~mm} . / \mathrm{hr}$.), and the presence of red and white blood cells, casts, and some protein in the urine, steroid therapy was started again. In April, 1963, chest and sinus $x$ rays were normal, blood pressure 155/95, blood urea $37 \mathrm{mg} . / 100 \mathrm{ml}$., and electrocardiogram normal.

Up to the time of writing, 9 months later, there has been little change in his general condition. He feels well apart from some frontal headache, and is on a maintenance dose of $15 \mathrm{mg}$. prednisolone per day.

\section{Discussion}

Godman and Churg (1954) and Walton (1958), in their reviews of cases of Wegener's granulomatosis, stated that the condition was characterized by a clinico-pathological triad of giant cell necrotic granulomatous lesions of the respiratory tract, widespread giant cell granulomata, and generalized necrotizing lesions of small blood vessels, without granulomatosis, especially in the kidney glomeruli, similar to those found in the microscopic type of polyarteritis nodosa. Godman and Churg further stated that "together these features are the identifying morbid characteristics, no one or two of which, in the absence of the others, serve to denominate the syndrome anatomically" although "certain of them represent milder or incomplete forms of a process fundamentally similar".

Walton believed that in this disease the primary lesion was a necrotic granulomatosis of the respiratory tract, possibly representing a type of Arthus phenomenon, and that the widespread granulomatosis and vasculitis appeared as a generalized hypersensitivity response to it. It has been suggested that the orbital granulomata found in such cases may arise in one of two ways: there may be direct contiguity, not always grossly obvious, with a primary lesion affecting one of the paranasal sinuses (Hogan and Zimmerman, 1962); or the orbital lesion may be one focal manifestation of the secondary widespread granulomatosis and vasculitis (Cutler and Blatt, 1956).

It will be noticed that the case here reported differs in certain important particulars from the above description of Wegener's granulomatosis. Histologically, although there is an orbital granuloma with evidence of vascular inflammation, there is no giant cell reaction, and little extravascular necrosis. Clinically, although there was nasal septum ulceration, this healed with simple medication before the initiation of steroid therapy, and when it recurred later, biopsy showed no evidence of necrotizing arteritis, and there was no perforation of the septum. Radiologically there was no evidence of sinus or pulmonary disease at any time.

There are two descriptions in the literature which seem to be particularly relevant to the present case. Hope-Robertson (1956) described a case presenting with unilateral proptosis. Biopsy of an orbital granuloma showed "thick-walled vessels with endarteritis, plasma cells, and eosinophils-a non-specific granuloma". Two years later the patient developed a generalized fatal illness and post mortem examination revealed widespread lesions typical of the microscopic form of polyarteritis nodosa. Walton (1959) described the post mortem findings, demonstrating widespread 
polyarteritis of the medium-sized vessel type in a patient who died a few months after presenting with an orbital granuloma. Histological examination of the original lesions showed a dense infiltrate of macrophages, plasma cells, lymphocytes, neutrophil and eosinophil polymorphs, and a few giant cells, but no necrosis, and there were only perivascular infiltrates about small arteries and veins, the walls of which were normal. Neither case resembles the histological descriptions of orbital lesions examined in cases of Wegener's granulomatosis, lacking signs of true necrotizing vasculitis and of tissue necrosis. Walton suggested that in his case the orbital granuloma might be the result, rather than the cause, of generalized polyarteritis nodosa, arising from the confluence of numerous perivascular infiltrates. The same opinion might be held in the present case, where the orbital lesions occurred quite late in the course of the generalized illness, and where there was histological evidence of true vasculitis as well as perivasculitis in the orbital granuloma.

There is, then, a spectrum of necrotizing inflammatory diseases, probably all with a basis of tissue hypersensitivity, ranging from the purely granulomatous (possibly including some other cases of pseudo-tumour of the orbit) to the purely vascular (typified by the classical forms of polyarteritis nodosa). There are intermediate mixed forms, of which Wegener's granulomatosis and allergic angiitis with granulomatosis (a condition described by Churg and Strauss (1951) and occurring exclusively in subjects with a definite history of allergy) are two specific examples. It would seem that we are concerned in this present case with yet another form of granulomatous polyarteritis nodosa, differing from these two in several respects, and possibly representing the incomplete form of Wegener's granulomatosis mentioned by Godman and Churg (1954).

From the clinical ophthalmic aspect, the necessity of considering necrotizing angiitis of the polyarteritis type as one possible cause of proptosis, especially in cases where there are concomitant symptoms of generalized disease, is indicated. With reference to the search for supportive clinical evidence for such a diagnosis, it may be added that very severe persistent headache accompanying the proptosis is possibly a suggestive symptom. This has been noted by several authors in their descriptions, and post mortem examination has, in some cases, demonstrated involvement of the meninges in the generalized vascular inflammatory process. In the present case, headache was the principal symptom throughout, and the raised cerebrospinal fluid protein content repeatedly found suggests that a similar process may be occurring here.

\section{Summary}

An unusual case of orbital granuloma is described, which presented in the course of a generalized illness considered to be polyarteritis nodosa. Histological examination of the orbital lesion showed the presence of necrotizing angiitis associated with granulomatosis. The aetiology is discussed with particular reference to cases of Wegener's granulomatosis, and the importance of considering such a condition in cases of orbital granuloma is stressed.

I wish to thank Dr. J. C. Linley-Adams, Mr. R. McNab Jones, Mr. J. E. A. O'Connell, and Dr. G. W. Hayward, under whose care the patient was at various times, for their permission to publish this case, and Prof. Norman Ashton and Mr. J. H. Dobree for their kind help and encouragement. 


\section{REFERENCES}

Churg, J., and Strauss, L. (1951). Amer. J. Path., 27, 277.

Coop, M. (1961). Brit. J. Ophthal., 45, 513.

CuTLER, W. M., and BlATt, I. M. (1956). Amer. J. Ophthal., 42, 21.

DUKE-ELDER, S. (1962). "System of Ophthalmology", vol. 7, p. 199. Kimpton, London.

FAULDS, J. S., and WEAR, A. R. (1960). Lancet, 2, 955 .

Godman, G. C., and ChURG, J. (1954). A.M.A. Arch. Path., 58, 533.

Hogan, M. J., and Zimmerman, L. E. (1962). "Ophthalmic Pathology", 2nd ed., p. 732. Saunders, Philadelphia.

HOPE-ROBERTSON, W. J. (1956). Trans. ophthal. Soc. N.Z., 8, 56.

RING, C. C. (1962). Ibid., 14, 87.

StraAtsma, B. R. (1957). Amer. J. Ophthal., 44, 789.

WALTON, E. W. (1958). Brit. med. J., 2, 265. (1959). J. clin. Path., 12, 419. 